\title{
El hispanismo historiográfico en perspectiva. Presentación del dosier.
}

\section{Historiographic Hispanism in perspective. Introduction to the dossier.}

Francisco García GonZÁLEZ

Universidad de Castilla-La Mancha

Francisco.ggonzalez@uclm.es

Hoy el hispanismo es una realidad bien consolidada. Su crecimiento ha sido tan intenso como amplio. Sin embargo, su progresión no ha sido algo improvisado. Detrás hay toda una larga historia. Comprender su origen y conocer su trayectoria y evolución nos ayudará a afrontar los retos del futuro. Un futuro que para algunos no está garantizado. O, al menos, no como lo conocemos hasta ahora. De hecho, están surgiendo voces que consideran que en la actualidad nos encontramos en un momento de incertidumbre, de encrucijada y hasta de crisis permanente.

Sin duda, el hispanismo tiene un marcado carácter filológico. De acuerdo al diccionario de la Real Academia Española, el término significa "dedicación al estudio de las lenguas, literaturas o cultura hispánicas". En consecuencia, el hispanista es el "especialista en la lengua y la cultura hispánicas". No obstante, en la práctica se emplea el término para designar al extranjero que se especializa en el estudio, en efecto, de los aspectos filológicos y culturales de la Península Ibérica y del mundo hispánico, pero también, con no menor interés, de su historia.

Este monográfico se centra precisamente en el ámbito historiográfico. El objetivo es presentar una panorámica del hispanismo y preguntarnos acerca del camino recorrido hasta aquí. Para ello, unos artículos harán hincapié en la genealogía del hispanismo en la historiografía, su proceso de surgimiento, crecimiento y desarrollo, su institucionalización académica y medios de consolidación, su tejido asociativo y sus vehículos de expresión en forma de revistas, publicaciones y otras fórmulas. Mientras, otros artículos nos presentan un balance historiográfico de las dos últimas décadas enlazando su fecunda vitalidad actual con una larga trayectoria en el pasado. Porque, ¿nos referimos a un hispanismo anticuado, trasnochado, agotado? ¿Cómo afronta el reto de hacer historia hoy? ¿Cómo se ha adaptado o se está adaptando al cambio historiográfico que vivimos? Y, en concreto, ¿qué lugar le corresponde en estos momentos dentro del proceso de renovación e internacionalización de la historiografía sobre el mundo hispánico? 
Es imposible reunir en un solo dosier contribuciones que representen a las distintas tradiciones y sensibilidades del hispanismo historiográfico. Como perspectiva de análisis se ha adoptado una estructura diferenciada por períodos históricos y no tanto por temas o países. Un planteamiento quizá clásico pero que es acorde con la línea editorial de transversalidad que viene desarrollando la revista Vínculos de Historia desde su creación. Somos firmes partidarios de favorecer e impulsar la imprescindible y siempre necesaria colaboración entre historiadores procedentes de distintas áreas y disciplinas. Reunir a especialistas con metodologías y problemática distintas pero que comparten el mismo interés por el hispanismo pretende también, en la medida de lo posible, contribuir a superar la fragmentación de su conocimiento y ampliar los horizontes segmentados que las divisiones académicas establecen.

En la segunda mitad del siglo $X X$ se produjo el gran auge del hispanismo historiográfico nacional con la enorme expansión de las universidades. Pero ni la evolución ni los ritmos seguidos por los diferentes hispanismos fue la misma. Conviene mirar al pasado para comprender similitudes y diferencias. Para ello, en este dosier reunimos a algunos de los principales especialistas que nos permitirán conocer comparativamente el origen y el desarrollo del hispanismo historiográfico en varios de los países donde más ha arraigado. Incluso, retrotrayéndonos a sus cimientos más remotos. Así, podemos contrastar el caso francés con el alemán y el anglonorteamericano (sin dejar de resaltar, en parte, las peculiaridades que diferencian también Inglaterra de Estados Unidos).

Porque, ¿cuándo empezó el hispanismo profesional en la historiografía? Para responder a esta cuestión, como hace Stanley G. Payne (Universidad de Wisconsin-Madison, EE.UU.) en su artículo, primero hay que distinguir entre términos como hispanista e hispanófilo dentro del conjunto de los escritores o aficionados con interés especial por España o su cultura. En su análisis, que inicia en el siglo XVIII, deja claro que el primer vocablo fue afianzándose a lo largo de la centuria siguiente para referirse a los estudiosos sobre el tema. El resto de los interesados serían los hispanófilos, autores que, sin dejar de escribir sobre España, lo hacían, no desde una perspectiva científica, sino con un sentido más divulgador y emocional, razón por la cual en muchas de sus obras se transmitían con frecuencia ideas míticas o románticas poco ajustadas a la realidad.

Antonio Niño Rodríguez (Universidad Complutense de Madrid) aporta un texto muy pertinente para introducirnos en las peculiaridades y diferencias del hispanismo francés con respecto al de otros países así como para comprender las razones de su extraordinario desarrollo. En su detallada radiografía encontramos las claves de su éxito: su excelente organización, su larga tradición y los sólidos apoyos institucionales con los que contó. Ayudas canalizadas en gran parte desde 1909 a través de la École des Hautes Études Hispaniques de Madrid, dependiente de la Universidad de Burdeos, que impulsó las actividades culturales que Francia realizaba en España. Una institución que ha sobrevivido hasta hoy al dar paso más tarde a la Casa de Velázquez (1928), el referente indiscutible del hispanismo galo en nuestro país tanto por su labor de formación en las más variadas especialidades como en su labor de intermediación para fomentar la colaboración entre instituciones, universidades e investigadores a un lado y otro de los Pirineos.

En este sentido, el artículo de Carmen Aranegui Gascó (Universidad de Valencia) permite aproximarnos desde el caso del hispanismo arqueológico francés a este contexto entre finales del siglo XIX y las primeras décadas del siglo XX. Ellos fueron los más predispuestos para resaltar la singularidad cultural de España a partir de obras y restos arqueológicos anteriores a la conquista romana. En su texto se centra en lo ocurrido con la cultura ibérica destacando, de manera especial, la importancia que tuvo la Dama de Elche. Convertida en figura emblemática y erigida como la prueba incuestionable de las raíces hispanas, su 
exhibición en el Museo del Louvre supuso introducir un estilo desconocido en los circuitos académicos de su tiempo y recabar la atención de otros arqueólogos europeos. No en vano, durante este período, España se convirtió en referente internacional en la investigación sobre Prehistoria e Historia Antigua gracias a la labor de los investigadores extranjeros. En concreto, Thomas Schattner (Instituto Arqueológico Alemán, Madrid) nos presenta una panorámica de los arqueólogos alemanes como hispanistas, abordando primero los antecedentes de su afición por España y el marco institucional que propició el desarrollo de sus trabajos. Para él, la influencia de España en Alemania fue mayor hasta mediados del siglo XIX. Después se invertiría esta relación a favor de los germanos. Pero, al margen de su idealización y admiración mutua, habría que esperar al período de entreguerras para que comenzara la instalación de centros de investigación en nuestro país. Y, como en Francia, este tipo de iniciativas fue paralela a la promoción de la política cultural exterior. La diferencia es que solo sería a comienzos de los años 40, una vez fundado el Instituto Alemán de Cultura, cuando la antigua idea de crear en España una sección del Instituto Arqueológico Alemán se materializaría. Desde entonces, gracias a su enorme actividad, en España se fueron documentando muchos de sus monumentos, desde la Prehistoria hasta la Edad Media.

Al contrario que en Francia y, en parte, en Alemania, el hispanismo británico no tuvo la misma expansión. Como analiza Payne, aun siguiendo en cierto modo un proceso similar, su desarrollo fue más lento y menos intenso. Al igual que en otros países, siempre primó el enfoque más filológico y literario, pero en relación a la historia, predominó la atención a la época más contemporánea, contrastando con el mayor peso del período moderno entre los hispanistas franceses o la arqueología entre los alemanes. En cualquier caso, en su opinión, el verdadero hispanismo en lengua inglesa surgió en los Estados Unidos y no en Inglaterra. Allí, durante la primera mitad del siglo XIX, destacaron grandes figuras que se preocuparon por la historia de España. Después, la perspectiva histórica pasaría a un segundo plano frente a la filológica hasta bien adentrado el siglo XX, momento en que comenzaron a brillar con luz propia algunos autores. Con unos lazos muy estrechos con la historiografía inglesa, en EE.UU. durante la dictadura franquista también prevaleció la inclinación por la época más contemporánea. Con posterioridad, fue incrementándose el número de investigadores especializados en el período medieval y moderno y, sobre todo, en América Latina, hasta el punto de que esta zona superaría la atracción que existía por la misma España.

En este momento, el francés y el norteamericano son los hispanismos más importantes. Si en Norteamérica lo es por el número de especialistas que lo ejercen, en Francia, Bernard Vincent (EHESS, Centre de Recherches Historiques) sigue afirmando —como hizo hace veinticinco años-, que el hispanismo historiador galo es el más denso del mundo. Una elevada productividad e intensidad que también ratifica Charles García (Centre d'Études Supérieures de Civilisation Médiévale, Universidad de Poitiers). Ambos países ponen de manifiesto cómo el hispanismo, gracias a su buena implantación en todo el tejido académico, ha crecido de forma muy considerable y ha dado lugar a una abundante producción que abarca todas las ramas de la historia. Un proceso paralelo al interés por el español que no ha dejado de aumentar en estos países con la entrada en el nuevo siglo.

A tenor de los resultados que nos aportan Charles García y Bernard Vincent para la época medieval y moderna, así como Kris Lane (Universidad de Tulane, EE.UU.) para América Latina en la época colonial, se puede afirmar que en la disciplina histórica el hispanismo vive en estas dos últimas décadas una situación especialmente brillante. Los datos son contundentes. El detallado análisis temático que nos presentan permite aproximarnos a algunos de los principales aspectos abordados en la actualidad por los historiadores hispanistas así como a las tendencias metodológicas más significativas. La elaboración de este tipo de balances tan minuciosos, exigen, como podrá comprobar el lector, un profundo 
conocimiento de la producción historiográfica. Las abundantes referencias bibliográficas que acompañan a cada uno de los textos así lo demuestra, algo que, sin duda, será muy útil para incentivar las investigaciones en el futuro más inmediato.

En líneas generales se constata que los temas tratados por los hispanistas reflejan el contexto historiográfico internacional y, de una manera más particular, los asuntos que priman en sus respectivas historiografías de origen. Así, mientras las investigaciones sobre la economía o los aspectos socioeconómicos reciben cada vez menos atención, el interés por la historia cultural y política (o sociopolítica), no deja de crecer. En este sentido, la historia rural, que contó con tanta tradición entre los hispanistas, casi ha desaparecido. Y, entre los medievalistas - menos entre los modernistas_- también se ha resentido el estudio de las ciudades.

La administración, el gobierno y los agentes de la monarquía, la interacción entre todos los poderes del reino y los procesos de negociación y un amplio listado de temas relacionados con los espacios del poder, son aspectos bastante investigados en el marco de la renovación de la historia política. Por su parte, la historia de lo religioso conoce un notable retorno con nuevos planteamientos que van desde lo más espiritual a lo más material pasando por los beneficios sociales derivados de invertir en sagrado. De una historia de la Iglesia preocupada por su dimensión institucional se está avanzando hacia investigaciones de mayor calado y profundidad que inciden en los aspectos más sociales y culturales. En especial, con respecto a América Latina donde las nuevas formas de abordar la religiosidad y asuntos tan problemáticos como la conversión o la denominada "conquista espiritual" están aportando novedosos resultados. Logros que desmienten antiguas simplificaciones al apostar por indagar sobre las ambigüedades propias de un mundo tan contradictorio y complejo como el colonial, difícil de encasillar en dicotomías como "vencedores y vencidos". La renovada historia de la esclavitud y de la trata de esclavos, de la herencia indígena, africana, asiática e hispana y de todo lo relacionado con la raza, el mestizaje y la sangre, son campos, con diferencia, de un extraordinario dinamismo. El mundo judío y converso, al-Ándalus, los mudéjares y los moriscos, siguen teniendo un incuestionable atractivo para los historiadores extranjeros cuando se habla de la historia de España y no son pocos los estudios que inciden en repensar la idea del tradicional atraso hispano ligado al oscurantismo y a la censura de la Inquisición como quería la Leyenda Negra.

La eclosión de investigaciones dentro del ámbito cultural no está exenta de polémicas por cuanto que, a veces, se presentan como un conjunto de resultados muy variados y no siempre bien articulados entre sí, propicios para el abuso de la generalización al no contar con una sólida base metodológica. En este sentido, dentro de un contexto intelectual marcado por el pensamiento postmoderno, la posibilidad de plantear las investigaciones al modo de los cultural studies es cada vez más una realidad. Riesgo del que advierte Antonio Niño en su contribución sobre el hispanismo francés que cuenta con una larga tradición en los estudios sobre civilización y que ahora pueden verse desvirtuados si se produce la pérdida de sus referentes fundacionales que estaban claramente entroncados con la historia. Una situación que puede acentuar el debate interno en Francia en torno a sus propias matrices disciplinarias.

Son muchos los aspectos contenidos en los balances realizados en este dosier. Con todo, hay que resaltar los relacionados con la integración de los diferentes espacios hispánicos. En primer lugar, peninsulares, algo que se incluye dentro de la sempiterna cuestión de la dialéctica unidad-diversidad de España. Y aquí Charles García constata por ejemplo cómo el espacio de la Castilla histórica, antaño prioritario, es en cierta forma desatendido por las nuevas generaciones de medievalistas mientras que se ha reactivado la atención por Cataluña o se profundiza en zonas antes más descuidadas como Asturias, León u otras al norte de los Pirineos. La tendencia hacia una especie de "occidentalización" 
de los estudios medievales peninsulares se corrobora con los trabajos existentes, aunque aún muy insuficientes, sobre el reino de Portugal.

En efecto, uno de los principales rasgos que caracterizan a estas dos décadas es la apertura de la investigación hispanista a otros ámbitos poco explorados hasta este momento. Como expone Vincent, "Ios horizontes han sido gradualmente ampliados. De una exclusiva atención a los territorios de la Península Ibérica (y con una marcada frontera entre España y Portugal) se ha pasado a la toma en consideración de todos los territorios europeos, africanos, americanos y asiáticos". Más allá de España y de sus diversos territorios, son muy ilustrativos de la nueva orientación del hispanismo los trabajos sobre las posesiones en Italia, Flandes o Portugal. Y junto a América y el Atlántico, importan también otros escenarios dispersos en Asia y África revisitando así un clásico concepto como el de frontera. Del mismo modo, como observa Lane, también en EE.UU. las nuevas orientaciones de la historia colonial en América Latina insisten en los lazos transatlánticos y en la emergencia de la historia global y conectada.

Lazos trasatlánticos contemplados a través de nuevas perspectivas de investigación como la historia de la familia, de las mujeres y del género, del estudio de redes o de trayectorias individuales y colectivas. Planteamientos que conceden un protagonismo esencial a los propios actores sociales, desde los burócratas a los mercaderes pasando por los emigrados y los esclavos, en paralelo al interés renovado por la movilidad.

En el juego de escalas que supone la investigación histórica cada vez es más evidente la práctica de una historia conectada a partir del análisis relacional de los propios actores sociales en sus diferentes contextos espaciales y temporales. Porque no es incompatible este tipo de metodologías con el proyecto de hacer una historia más global dado que todas las escalas, de lo micro a lo macro, son útiles para el historiador como afirma Bernard Vincent. El reto sigue siendo cómo integrar la delimitación temporal y espacial de los estudios con los planteamientos a largo plazo y referidos a territorios amplios si queremos, como denunciaban en su manifiesto por la historia Jo Guldi y David Armitage, superar el fantasma del corto plazo. 